Revista Eletrônica História, Natureza e Espaço - ISSN 2317-8361 v. 3, n. 2 (2014)

DOI: 10.12957/hne.2014.20266

\title{
As múltiplas tensões das relações espaciais da Baía de Guanabara: breves considerações acerca dos conflitos pelo uso dos diferentes territórios.
}

Jessica Fernandes

Graduado em licenciatura em Geografia com ênfase em Meio Ambiente pela UERJ/FEBF

jessica_damiana@hotmail.com

\section{Resumo}

Com uma arquitetura de contrastes, a Baía de Guanabara vem desde a chegada dos portugueses sendo um dos elementos de grande destaque na paisagem natural do Rio de Janeiro. Ao longo de sua história, esse espaço veio sofrendo inúmeras transformações, principalmente mudanças causadas pela ação antrópica em sua área. Atualmente a Baía se apresenta como um espaço de tensões e disputas entre a indústria petroquímica e as populações que de alguma forma dependem desse espaço para manutenção de suas culturas e sobrevivência. Diante dessas colocações, o presente trabalho tem como objetivo analisar brevemente o uso do espaço da Baía de Guanabara ao longo dos séculos, os elementos que atualmente compõem esse espaço e o tornam um território de disputa, gerando os conflitos socioambientais que emergem das relações e interrelações dos sujeitos que atuam nesse espaço.

Palavras-chaves: Baía de Guanabara; Conflitos Socioambientais; Uso do espaço.

\section{Resumo}

Con una arquitectura de contraste, la Bahía de Guanabara desde la llegada de los Portugueses, viene siendo uno de los elementos de gran destaque en el paisaje natural de Río de Janeiro. A lo largo de su historia, este espacio ha venido sufriendo muchos cambios, especialmente los cambios causados por las actividades humanas en su área . Actualmente la Bahía se presenta como un espacio de tensiones y disputas entre la industria petroquímica y personas que de alguna manera dependen de este espacio para el mantenimiento de sus culturas y de su supervivencia. Teniendo en cuenta estos parámetros, el presente trabajo tiene como objetivo analizar brevemente el uso del espacio de la Bahía de Guanabara a lo largo de los siglos, los elementos que componen actualmente el espacio y la convierten en una guerra territorial, generando conflictos ambientales que surgen de las relaciones y inter -relaciones de los sujetos que operan en este espacio.

Palabras clave : Bahía de Guanabara ; conflictos socio- ambientales; Uso del espacio. 


\section{Introdução}

A Baía de Guanabara é um espaço complexo, composto por diferentes elementos que em suas relações e inter-relações dão esse espaço a sua atual e complexa dinâmica. A situação atual da Baía é fruto de um longo processo histórico de degradação desse ambiente, que está diretamente relacionado aos interesses do capital nacional e internacional. Ao longo de sua história esse espaço veio sofrendo inúmeras transformações, principalmente mudanças causadas pela ação antrópica em sua área. Atualmente a Baía se apresenta como um espaço de tensões e disputas entre a indústria petroquímica e as populações que de alguma forma dependem desse espaço para manutenção de suas culturas e sobrevivência.

Diante dessa complexidade é necessário que para uma análise eficaz que corresponda à realidade tenhamos uma metodologia bem definida. Optamos nesse trabalho por utilizar o conceito de espaço apresentado por Santos (2012), que considera o espaço como uma totalidade. Considerar o espaço como uma totalidade é apenas uma regra de método para realização de sua analise. Toda análise gera uma fragmentação da realidade, dividindo-a em partes, que ao final do processo deverão ser novamente reunidas, compondo assim a realidade, que sempre será superior ao somatório dessas partes. Há diversas possibilidades de dividir o espaço em partes para sua analise, nesse trabalho optamos por dividir o espaço em elementos, que serão chamados de Elementos do Espaço (SANTOS, 2012). Para analisar o complexo espaço da Baía de Guanabara, optamos por utilizar esse método de análise.

Elegemos um primeiro momento, no qual identificamos a presença desses elementos na composição da dinâmica do espaço da Baía de Guanabara para que, após a análise, tomada individualmente, seja possível fazer relação entre eles e que se possa identificar as principais tensões presente do espaço da Baía.

Ao longo da evolução urbana do Rio de Janeiro, a Baía de Guanabara vivenciou um processo de grandes transformações, não apenas em seu entorno, mas também no seu espelho d'gua. As suas funções e formas foram sofrendo modificações ao longo da evolução do Rio de Janeiro, as primeiras atividades econômicas, o crescimento da 
cidade, a falta de saneamento, e as intervenções urbanas realizadas ao logo de toda essa transformação, são apenas uma pequena parte de todo um processo de degradação desse importante ecossistema.

O processo de industrialização iniciado nos anos 1930 e intensificado no país nos anos 1950, teve papel fundamental na intensificação da poluição das águas da Guanabara (com consequências, naturalmente, sobre os demais elementos desse espaço). Com essa nova atividade a Baía recebe novas funções, deixando de estar a serviço da produção, para se tornar um espaço efetivo dela (trecho truncado. Melhor excluir). A instalação da refinaria REDUC em Duque de Caxias (RJ), pode ser interpretada como a "sentença de morte" da Baía de Guanabara, pois as consequências não apenas dos resíduos lançados em suas águas, mas também da poluição em seu entorno, passa a ser a fonte do principais problemas socioambientais presentes nessa região até os dias atuais.

Diante do exposto o presente trabalho tem por objetivo analisar brevemente as relações espaciais na Baía de Guanabara e que colocam esse ambiente como um espaço em disputa e composto por múltiplas tensões em seu uso.

\section{A Baia de Guanabara e suas múltiplas tensões}

A Baía de Guanabara ocupa uma área de $380 \mathrm{~km}^{2}$, composta não apenas pelo espelho d'água da baía, mas por todas suas ilhas, ilhotas e pedras. A maior extensão é de $38 \mathrm{~km}$ entre a barra e foz do rio Magé, e sua maior largura é de $28 \mathrm{~km}$ entre a foz dos rios São João de Meriti e Guapi Macau (COELHO, 2007). O mapa a seguir apresenta os munícipios que se encontram no entorno da Baía de Guanabara, e que atuam de forma direta na dinâmica desse espaço.

\section{Mapa 1. A Baía de Guanabara e os munícipios do seu entorno}

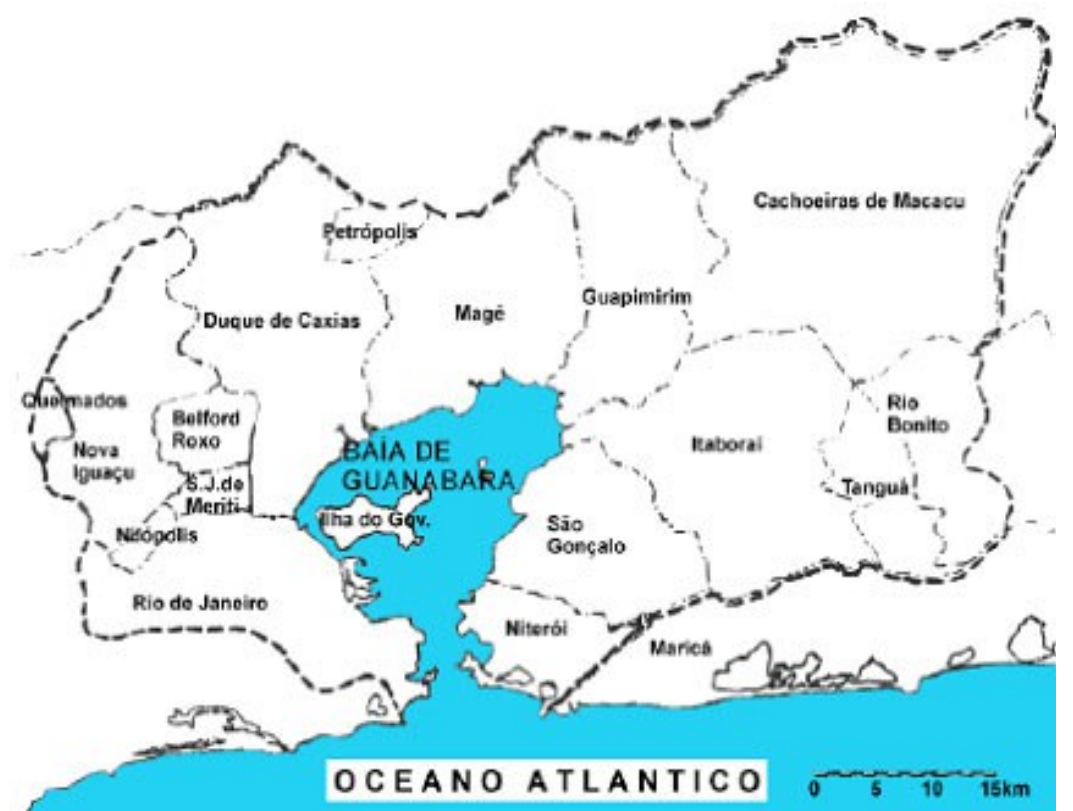


Fonte: http://www.planetabilidade.com.br

Ao longo dos séculos, destacadamente a partir do século XVI (quando se acirraram as disputas entre portugueses e franceses pela então França Antártica), as transformações no entorno do espaço da Baía de Guanabara, levou a profundas transformações em sua dinâmica natural, e principalmente na forma de uso desse espaço, assumindo funções sempre relacionadas à dinâmica e aos interesses do capital.

De acordo com o geógrafo Milton Santos (2012):

"Sempre que a sociedade (a totalidade social) sofre uma mudança, as formas ou objetos geográficos (tanto os novos como os velhos) assumem novas funções; a totalidade da mutação cria uma nova organização espacial. Em qualquer ponto do tempo, o modo de funcionamento da estrutura social atribui determinados valores às formas" (p.67).

Em cada momento do constante processo de mudança que são experimentas e vividas no espaço, há uma reorganização das estruturas, formas e funções que ele apresenta atendendo, proeminentemente, à lógica da acumulação capitalista.

\section{Esquema sobre o processo de mudança das funções da Baía de Guanabara}

Segundo Santos (2012) a função está associada à "tarefa ou atividade esperada de uma forma, pessoa, instituição ou coisa" (p.53). As inúmeras funções que a Baía de Guanabara vivenciou ao longo de sua história, estiveram sempre ligadas à lógica de interesse do Estado, buscando sempre gerar maiores lucros. Essas inúmeras funções, não foram sendo substituídas uma pela outra, mas se apresentam em uma relação dialética de superação, no sentido de que os diversos usos do solo foram se sobrepondo, num intenso processo que se tornou cumulativo, respondendo a cada necessidade 
relativa às fazes de desenvolvimento do capitalismo. As transformações dessas funções foram marcadas por conflitos acerca do uso desse espaço. Atualmente o cenário é marcado pela intensificação de disputas desse território, que passa a ser fundamental na lógica da reprodução do capital, e que possui em seu interior, inerentemente, uma considerável quantidade de conflitos e tensões.

Quadro 1. As múltiplas funções da Baía de Guanabara ao longo dos séculos

\begin{tabular}{ll}
\hline Funções da Baía & Período histórico \\
\hline Pesca Artesanal & Colonização - século XVI \\
Defesa & Colonizção - século XVI \\
Portuária & Século XVII até os dias atuais \\
Produção de Cana-de-Açúcar & Desenvolvimento - século XVI \\
Aterros & Século XVII até a metade do séc. XX \\
Transferência da Capital para o Rio de & Século XVIII \\
Janeiro & \\
Portuária/transporte (mineração) & Século XVII \\
Portuária/transporte (café) & Século XIX \\
\hline
\end{tabular}

Atualmente, o interesse do capital faz com que este espaço passe a ser de extrema importância para diferentes atores sociais, que irão disputar o uso da Baía gerando conflitos e tensões que serão analisados no decorrer deste artigo. Para que possamos apontar e compreender os fenômenos e tensões presentes no espaço da Baía de Guanabara, é necessário esclarecer o que entendemos como espaço e como iremos analisá-lo. A ideia exposta por Santos (2012) sobre uma das possibilidades de análise do espaço é a que utilizaremos neste trabalho.

O espaço deve ser considerado como uma totalidade, a exemplo da própria sociedade que lhe dá vida. Todavia, considerá-lo assim é uma regra de método cuja prática exige que se encontre, paralelamente, através da análise, a possibilidade de dividi-lo em partes. Ora, a análise é uma forma de fragmentação do todo que permite, ao seu término, a reconstituição desse todo. Quanto ao espaço, sua divisão em partes deve poder ser operada segundo uma variedade de critérios. O que vamos privilegiar através do que chamamos "os elementos do 
Diante do método proposto por Santos (2012), buscamos fragmentar o espaço, elencando seus elementos e os analisando separadamente, para que ao final possamos reconstruir essa totalidade, e, enfim, compreender como a relação entre esses elementos tornam o espaço da Baía um território de disputa entre os sujeitos que estão presentes na sua dinâmica. Segundo Santos (2012) são considerados elementos do espaço: os homens, as firmas, as instituições, o meio ecológico e as infraestruturas. No caso da Baía de Guanabara, podemos identificar esses elementos na figura dos pescadores, bases militares, portos, indústrias, entre outros.

Os Homens são considerados elementos do espaço, porém, quando se apresentam na qualidade de trabalhadores, necessário se faz enfatizar as relações sociais, para que não o reduzamos a mero fator produtivo. Na Baía, podemos tomar como exemplo desse elemento os trabalhadores (pescadores, petroleiros, entre outros), portanto, essa categorização do trabalho nos permite revelar a especificidade dos conflitos que então vão se estabelecendo.

O tecido dos conflitos se materializam ao identificarmos o outro polo sobre o qual se materializam as tensões. Ele é representado pelas firmas, cujo papel é a produção de bens de serviços e ideias, se apresentando na Baía através das Barcas S.A., Petrobras e Petroflex.

As instituições, no caso daquelas que são representadas pelo Estado, são responsáveis pela produção de normas, ordens e legitimações de determinados processos. Podemos, tomar como exemplo das instituições presentes na Baía, o Estado através dos governos Estaduais e Municipais ou as ONGs como a Fundação OndAzul.

As infraestruturas se apresentam na forma do trabalho humano materializado, como casas, plantações, estradas, entre outros. Na Baía o exemplo desse elemento pode ser observado através da presença de portos, fortes, indústrias e colônias de pescadores.

O Meio Ecológico é o conjunto de complexos territoriais que constroem a base fixa do trabalho humano. Como exemplo desse elemento na Baía de Guanabara podemos citar seus rios, praias, vegetações, entre outros. 
O reconhecimento desses elementos nos permite identificar os principais sujeitos que estão atuando no espaço da Baía. É fundamental destacar que cada elemento possui uma função no espaço ao qual se encontra vinculado. Entretanto, essas funções não são tomadas de forma absoluta: os homens podem ser tomados como componentes das firmas, quando vendem sua força de trabalho, ou até mesmo como instituições, ao assumirem seu papel de cidadão e estão vinculados a algum movimento social, que apresente algum reconhecimento local. As próprias firmas frequentemente assumem também o papel de instituições, pois, de certo modo, também criam normas, que, sob certas circunstânciasas, alcançamo algum nível de legitimidade, sobretudo quando analisamos mais acuradamente suas relações com o Estado, ou quando este cria as normas que beneficiam as atividades do setor privado.

Dentre os diversos agentes, aqueles que mais sofrem as consequencias dos processos desencadeados na Baía de Guanabara são os pescadores artesanais. São constantemente ameçados com os impactos da poluição, da mortandade de peixes e de outras vulnerabilidades, relativas a elevada carga da elementos tóxicos em função do desenvolvimento das atividades das empresas que se estabeleceram na Baía. Destaque deve ser dado a ameaça sobre a extinção da atividade pesqueira, que vai além do trabalho, mas de suas tradições, as quais incluem seu trato com o meio ambiente e, de certa maneira, aponta para sua preervação. Constitui um momento em que se captura a coincidência entre preservação da natureza e preservação da vida na sua integralidade, ou seja, a preservação dos elementos naturais se aproxima da preservação da própria humanidade. Talvez seja esse o principal ensinamento que as comunidades pesqueiras tenha a nós legar.

Os homens (no caso desses pescadores) podem também aparecer como o elemento firma, quando se apresentam na forma de cooperativa de pescadores, sendo responsáveis pela produção de bens e ideias coletivas. Assumem a forma do elemento instituições, quando se organizam e instituem sindicatos ou organizações como a $\mathrm{AHOMAR}^{1}$, passando dessa forma a produzirem normas e terem um papel de Homens do Mar) é uma associação que reúne pescadores artesanais além de outras entidades de pesca, as chamadas associações co-irmãs, que unem-se em projetos e luta por direitos (DUARTE apud CHAVES, 2011) 
Revista Eletrônica História, Natureza e Espaço - ISSN 2317-8361 v. 3, n. 2 (2014)

DOI: 10.12957/hne.2014.20266

legitimação junto aos pescadores. $\mathrm{Na}$ forma do elemento infraestrutura, os homens aparecem ainda através da produção de suas paisagens, cuja materialidade e simbolismos compõem as colônias de pescadores, sendo estas a materialização do trabalho humano, a qual devemos associar os modos de ver, viver e sentir o mundo.

Essas múltiplas funções são possíveis, pois apesar de analisados separadamente, cada um dos elementos do espaço possui uma relação/inter-relação entre si, momento que se abre para, a partir dessa fragmentação (divisão dos elementos), possamos através da reconstrução dessas partes analisar o todo que constitui o espaço em questão. $O$ esquema a seguir busca sintetizar essas múltiplas funções que um mesmo elemento pode assumir, buscando demonstrar através dele que todos os elementos possuem relação entre si.

Esquema 2. Síntese das múltiplas funções dos Elementos do Espaço na Baía de Guanabara

\subsection{As tensões e suas dimensões}

As relações e inter-relações apresentadas entre os elementos do espaço, homens, firmas, instituições e infraestruturas, presentes na Baía de Guanabara acabam gerando inúmeras tensões em seu interior. Para Pacífico (2011) todas essas tensões se encontram profundamente interligadas entre si. Para que possamos analisar esses conflitos tomaremos como base, a ideia proposta pelo autor de que essas tensões sejam analisadas 
a partir de quatro dimensões: ambiental, infraestrutural, político-administrativa e logística.

Antes de iniciar a análise das tensões a partir dessas dimensões, gostaríamos de fazer uma pequena consideração a respeito da dimensão ambiental. Entendemos que a dimensão ambiental contempla as tensões que se revelam a partir da relação do homem com o ambiente, e dessa forma respeitamos a proposta feita pelo autor, porém optamos por utilizar neste trabalho o termo socioambiental para nos referirmos a essa dimensão. Por considerarmos que as tensões surgem a partir da relação do homem com o ambiente, entendemos que a dimensão socioambiental, ou ambiental para Pacífico (2011), contempla em seu interior os conflitos que surgem a partir da análise por outras dimensões. As tensões (conflitos) só se apresentam a partir do momento em que o homem/sociedade dá ao ambiente um determinado valor, e passa com isso a disputá-lo de alguma forma. Acreditamos ser o termo socioambiental mais adequado para as relações presentes na Baía de Guanabara. Dessa forma a dimensão ambiental proposta por Pacífico (2011) será trabalhada neste trabalho como dimensão socioambiental. Diante de essas considerações o esquema a seguir tem como objetivo sintetizar a forma como estamos considerando as dimensões de analise nesse trabalho.

\section{Esquema 2 - Dimensões de análise do espaço da Baía de Guanabara}

Para Santos (2012):

\footnotetext{
Se considerássemos a população como um todo, as firmas como um todo, a nossa análise não levaria em conta as múltiplas possibilidades de interação. Ao contrário, quanto mais sistemática for a classificação tanto mais claras aparecerão as relações sociais e, em consequência, as chamadas relações espaciais. (SANTOS, 2012, p. 23)
}

É sob essa perspectiva que verificamos que a análise feita através das dimensões e os conflitos que dela emergem, assim como o caso dos elementos, não são limitados a 
elas, e possuem relações e inter-relações com as demais. Os elementos do espaço estão presentes nas tensões que surgem a partir dessa análise, sendo através de suas trocas que essas tensões se constituem. Perceber essas múltiplas interações é que irá nos permitir uma análise mais próxima da realidade dos conflitos presentes na Baía de Guanabara.

A primeira dimensão de análise é a socioambiental, que irá contemplar os conflitos gerados pela grande degradação ambiental, que como já apresentamos anteriormente, a qual vem se estendendo ao longo dos séculos na Baía de Guanabara. Os conflitos que emergem através dessa análise e nas demais, como veremos posteriormente, tem suas bases nas relações entre os elementos do espaço presentes na Baía. No caso dos conflitos de dimensões socioambientais podemos apontar como exemplo, o embate entre os pescadores (HOMENS) e a Refinaria Duque de Caxias REDUC (FIRMAS), que disputam desde a instalação dessa empresa o uso do espaço da Baía de Guanabara. Outros exemplos podem ser citados, como as tensões geradas pela poluição das águas da Baía por derramamento de óleo (por partes das indústrias petroquímicas que representam as FIRMAS), que consequentemente prejudica a qualidade do pescado, fundamental para a sobrevivência dos pescadores (HOMENS). A fotografia a seguir tirada pelos pescadores durante um conflito entre eles e a REDUC nos permite identificar a disputa pelo uso do espaço da Baía.

Figura 1 - Conflito entre pescadores e REDUC

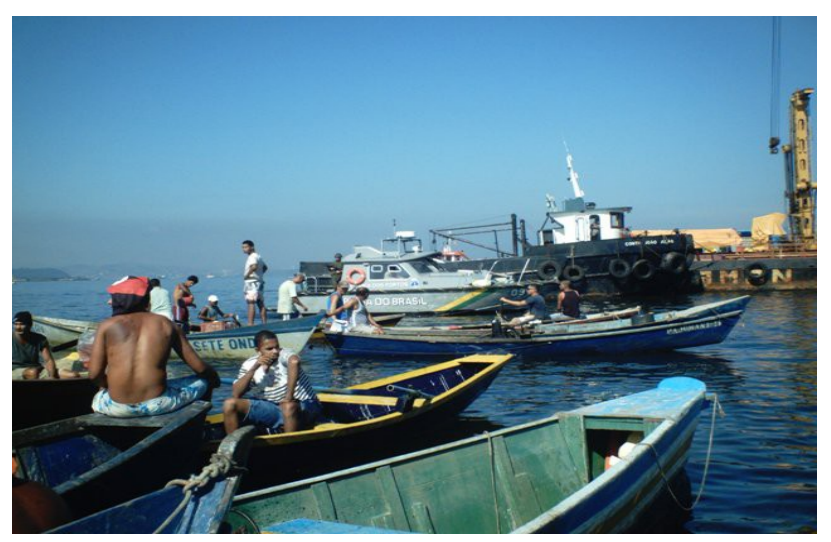

Fonte: Imagem disponibilizada pelo pescador Alexandre Anderson durante palestra no Seminário 50 anos de REDUC: ganhos, perdas e danos, realizado na Faculdade de Educação da Baixada Fluminense entre os dias 16 e 17 de setembro de 2011.

No que se refere a segunda dimensão, no caso a infraestrural, novamente podemos apontar conflitos entre a REDUC e os pescadores. Os dutos de transmissão de gases da indústria petroquímica (INFRAESTRUTURAS) fazem com que o espaço de pesca seja reduzido, limitando assim as áreas disponíveis para que os pescadores 
(HOMENS) circulem com seus barcos. A fotografia a seguir faz referência a esse tipo de conflito presente na Baía.

Foto 2 - Faixas de repúdio as obras de infraestrutura da REDUC

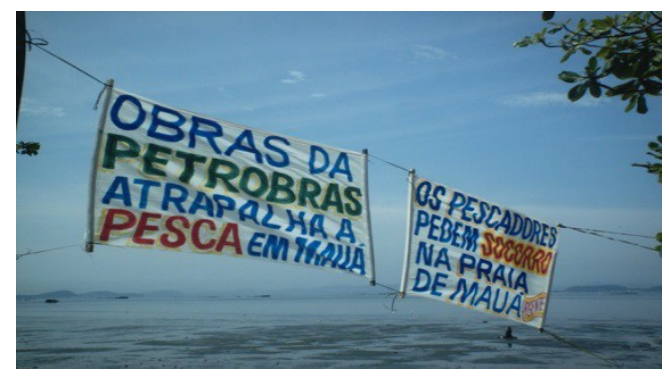

Fonte: Imagem disponibilizada pelo pescador Alexandre Anderson durante palestra no Seminário 50 anos de REDUC: ganhos, perdas e danos, realizado na Faculdade de Educação da Baixada Fluminense entre os dias 16 e17 de setembro de 2011.

A partir da análise feita a partir da dimensão político-administrativa, encontramos conflitos ligados às INSTITUIÇÕES, representadas pelos diversos municípios que estão diretamente ligados a região do entorno da Baía. As diferenças entre esses governos acabam gerando dificuldade na formulação de propostas para a recuperação ambiental da Baía.

De acordo com Pacífico (2011) a Região hidrográfica da Baía de Guanabara é uma das mais dinâmicos entre os espaços do território nacional em termos de fluxos (de pessoas, de mercadorias, de bens e serviços) constituindo-se como importante centralidade. Essa colocação demonstra a importância logística do espaço da Baía, e a análise a partir dessa dimensão nos permite identificar algumas tensões. Citamos novamente como exemplo a disputa entre a REDUC (FIRMA) e os pescadores (HOMENS). Essa tensão se dá na disputa pela circulação na Baía, de um lado a REDUC necessita do espelho d'água para passar seus dutos de transmissão de gàs; de outro lado os pescadores utilizam esse mesmo espelho d'água para transitarem com seus barcos. A fotografia abaixo nos permite identificar como esse espaço é disputado em termos de logística entre esses sujeitos. Podemos identificar na fotografia a presença das embarcações próximas aos dutos da refinaria, disputando o mesmo espaço de circulação. 
Figura 3 - Pescadores e dutos da REDUC

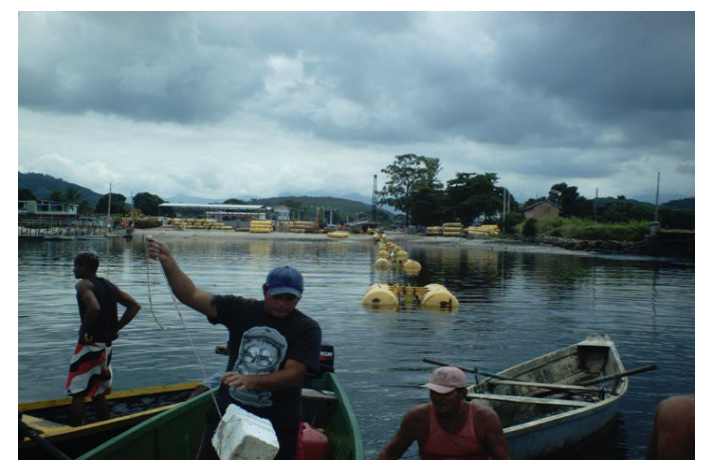

Fonte: Imagem disponibilizada pelo pescador Alexandre Anderson durante palestra no Seminário 50 anos de REDUC: ganhos, perdas e danos, realizado na Faculdade de Educação da Baixada Fluminense entre os dias 16 e17 de setembro de 2011.

A repetição desse exemplo, porém, através de diferentes dimensões de análise, é possível, pois os conflitos que aparecem de acordo com essas dimensões não se resumem a elas. Assim como os elementos do espaço possuem inter-relações, os conflitos revelados através dessas dimensões também apresentam essas inter-relações. Os conflitos e tensões que emergem a partir da análise feita pelas dimensões, nos permitem identificar e apontar a Baía de Guanabara como um território de disputa, onde diferentes interesses e identidades para com esse espaço são colocados.

\subsection{Baía de Guanabara: Território de disputa}

Observamos que o espaço da Baía de Guanabara tem se intensificado como uma arena de conflitos e tensões, onde diferentes interesses se chocam em relação a forma de uso desse espaço. Nesse sentido, se definirmos a Baía como um território de disputa (ou em disputa) por diferentes atores sociais é necessário que se faça uma pequena reflexão sobre o uso desse termo, sua definição e a forma como estamos entendendo e aplicando essa categoria para nossas análises sobre esse dinâmico espaço da Baía.

Segundo Santos e Silveira (2012):

Por território entende-se geralmente a extensão apropriada e usada. Mas o sentido da palavra territorialidade como sinônimo de pertencer àquilo que nos pertence...esse sentimento de exclusividade e limite ultrapassa a raça humana e prescinde a existência do Estado. Assim, essa ideia de territorialidade se estende aos próprios animais, como sinônimo de área de vivência e de reprodução. Mas a territorialidade humana pressupõe também a preocupação 
com o destino, a construção do futuro, o que, entre os seres vivos, é privilégio do homem (p. 19).

Haesbaert (2003) apresenta três vertentes de territórios possíveis: Jurídicopolítica, cultural(ista) e econômica. A vertente Jurídico-política seria a mais difundida, representada através do poder político do Estado, essa vertente define território como um espaço delimitado, controlado pelo poder, ou em outro sentido mais restrito território seria o nome político para o espaço de um país (SANTOS e SILVEIRA, 2012), pois estaria ligado ao poder do Estado.

A vertente cultural(ista) apresenta o território como um produto da valorização de um grupo sobre seu espaço, ou seja da apropriação do determinado grupo sobre o espaço (HAESBAERT, 2003). No caso da Baía essa vertente de território estaria sendo apropriada pelos pescadores, que possuem uma relação mais simbólica e de apropriação do espaço da Baía de Guanabara. Dessa forma território está ligado a uma lógica relacionada ao poder, mas não apenas o poder político, mas tanto a um poder no sentido mais concreto, de dominação, quanto ao um poder num sentido mais simbólico, de apropriação (HAESBAERT, 2005).

No caso da vertente Econômica, bem menos difundida, o território está relacionado às relações econômicas. Nesse caso podemos citar a afirmação de Santos e Silveira (2012) de que "o uso do território pode ser definido pela implantação de infraestruturas, [...] mas também pelo dinamismo da economia e da sociedade" (p. 21). Nessa lógica essa vertente tem como representantes na Baía as Firmas como, Petrobras, Petroflex, as colônias de pescadores e o próprio Estado, que de alguma forma buscam a organização desse espaço diante de suas lógicas e interesses.

As diferentes vertentes de territórios apresentadas por Haesbaert (2003), podem estar presentes em um espaço incomum, cada uma ocorrendo de acordo com os sujeitos que disputam o uso desse território. Tal fato é possível pois um mesmo espaço pode conter vários territórios, de um grupo ou de vários grupos (CHAVES, 2011), de forma que:

Mesmo que haja dois territórios em um mesmo lugar, representando territorialidades de grupos diferentes, contanto que sigam a mesma lógica capitalista e não sejam concorrentes é possível manter uma harmonia. No entanto, caso as territorialidades tenham ideologias 
opostas, o conflito e a disputa pela "soberania" territorial entram em conflito (CHAVES, 2011, p.75).

O espaço da Baía de Guanabara apresenta-se exatamente dentro dessa lógica de oposição de ideologias apresentada pela autora. Ao mesmo tempo a Baía pode ser vista dentro das vertentes jurídico-política, cultural(ista) e econômica, porém as diferentes territorialidades vivenciadas por cada uma delas fazem com que a Baía de Guanabara seja um espaço complexo de disputa.

A valorização do espaço da Baía de Guanabara dentro da atual fase do capitalismo, se dá como já vimos anteriormente pela necessidade de reprodução do capital, que cada vez mais busca novas áreas para aumentar os lucros. Podemos tomar o apontamento de Harvey (1980) como exemplo para explicar essa lógica de valorização e analisar melhor como ela se aplica na Baía.

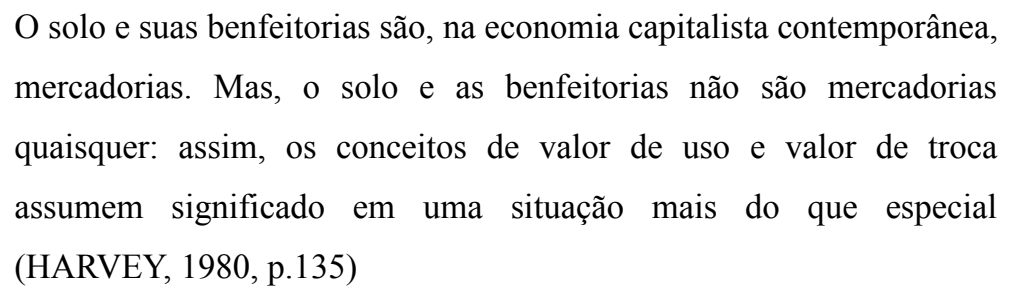

Para o autor a palavra valor pode apresentar dois sentidos: "algumas vezes expressa a utilidade de algum objeto particular e algumas vezes o poder de compra de outros bens que a posse daquele objeto transmite. O primeiro pode ser chamado 'valor de uso' e o 'outro valor de troca'. (HARVEY, 1980, p.131)

No caso da Baía de Guanabara o solo seria equivalente ao seu espelho d'agua, que irá ser disputado entre diferentes sujeitos, como as grandes empresas multinacionais, o Estado e grupos tradicionais como os pescadores artesanais, que terão valores diferentes para com esse espaço, valores esses que implicarão em uma disputa pelo uso da Baía.

Os pescadores artesanais que se apresentam como exemplo da Vertente cultural(lista) sobre o território, se apropriam do espaço da Baía de uma forma mais tradicional, sendo esse o seu espaço de sobrevivência e de manutenção de sua cultura. Segundo Lefebvre (1986), a apropriação seria um processo marcado pelo valor simbólico, do espaço vivido, carregado de valor de uso. 
Para Harvey (1980), "esse valor de uso não é o mesmo para todas as pessoas [...] Cada indivíduo e grupo determinará, diferentemente, o valor de uso" (p.136). Assim, para os pescadores esse valor de uso estará fortemente marcado pelas marcas do vivido. Dentro desta lógica, para o autor, "o valor de uso, concebido em seu sentido cotidiano, "permanece fora da esfera da economia política" (HARVEY, 1980, p.137), o que significa que no caso da Baía, apesar desse valor ser diferentemente determinado por cada sujeito, as grandes multinacionais, como a Petrobrás, estariam ligadas a outro tipo de uso do espaço, pois a sua lógica é a de acumulação de capital.

Essas grandes corporações, assim como o Estado estariam ligados a um uso associado à dominação, que seria um processo marcado pela funcionalidade do espaço, um espaço caracterizado pelo valor de troca em detrimento do valor de uso (LEFEBVRE, 1986).

\section{Considerações Finais}

Diante dessas colocações é possível percebemos como a Baía é um espaço complexo, onde podemos identificar diferentes conflitos e tensões entre os elementos que compõem esse dinâmico espaço de acordo com as diferentes formas de análise que utilizamos.

Esses conflitos e tensões como vimos no decorrer do capítulo, são resultado de um processo histórico de desenvolvimento, onde a Baía assume diferentes funções, até que passa a ser um espaço efetivo de produção, colocando em "choque" diferentes interesses, e maneiras de lidar com o local. Um dos principais conflitos, e disputas pelo uso do espaço/território da Baía entre os elementos que o compõe, é em relação a atuação de atores que sustentam o elemento Homem (na qualidade de pescadores) e as Firmas (as grandes multinacionais petroquímicas, principalmente a Petrobrás/REDUC).

Os conflitos e tensões entre esses elementos vem crescendo atualmente, e a cada dia toma mais espaço nas discussões realizadas entre os movimentos sociais (ONGs, fóruns, sindicatos de trabalhadores, pois atuam diretamente no espaço da Baía). Reconhecer os elementos que atuam nesse espaço, e como ele se torna um território de disputa é fundamental para que possamos entender como essas tensões e conflitos podem ser analisados pelas instituições que compõem os movimentos sociais. 
Referências

CHAVES, Carla Ramôa. Mapeamento Participativo da Pesca Artesanal da Baía de Guanabara. Dissertação (Mestrado em Geografia) - Universidade Federal do Rio de Janeiro, 2011.

COELHO, Victor M. B. Baía de Guanabara: uma história de agressão ambiental. Rio de Janeiro: Casa da Palavra, 2007. 278p.

HAESBAERT, Rogério. Da Desterritorialização à Multiterritorialidade. In: Boletim Gaúcho de Geografia. Porto Alegre: v. 29, p. 11 - 24, 2003.

. Da Desterritorialização à Multiterritorialidade. In: Anais do X Encontro de Geógrafos da América Latina - 20 a 26 de março de 2005 Universidade de São Paulo, 2005. Disponível em: http://www.planificacion.geoamerica.org/textos/haesbaert multi.pdf, acessado em 15 de Janeiro de 2013.

HARVEY, David. A justiça social e a cidade. São Paulo: Hucitec, 1980. 291p.

O Novo Imperialismo. 5 5ae edição. São Paulo: Edições Loyola, 2011.

LEFEBVRE, H. La Production de l'Espace. Paris: Anthropos, 1986.

PACÍFICO, Alan. O Espaço da Baía de Guanabara e suas múltiplas tensões: uma abordagem geográfica e multidimensional para a compreensão do planejamento e gestão de seu sistema de circulação. I Simpósio de Estudos Urbanos - Desenvolvimento Regional e Dinâmica Ambiental, 2011. Disponível em:

http://www.mauroparolin.pro.br/seurb/Trabalhos/EIXO 1 PLANEJAMENTO E GESTAO URBANA 16 ARTIGOS/PACIFICO COMPLETO O ESPACO D A BAIA DE GUANABARA E SUAS MULTIPLAS TENSOES.pdf, acessado em 15 de Janeiro de 2013.

SANTOS, Milton. Espaço e método. 5ª edição. São Paulo: EdUSP, 2012. 
Revista Eletrônica História, Natureza e Espaço - ISSN 2317-8361 v. 3, n. 2 (2014)

DOI: 10.12957/hne.2014.20266

; SILVEIRA, María Laura. O Brasil - Território e Sociedade no início do século XXI. 16 ${ }^{\mathrm{a}}$ edição. Rio de Janeiro: Record, 2012. 